\title{
Unexplained changes on a psychiatric pregnancy study(Letter)
}

- Chang-Cabanillas, S.Email Author,

- Alarcón-Guevara, S.,

- Peñafiel-Sam, J.,

- Tejada, R.A.

- View Correspondence (jump link)

- Escuela de Medicina, Universidad Peruana de Ciencias Aplicadas (UPC), Lima, Peru

Abstract_View references (5)

[No abstract available]

- ISSN: 14341816

- CODEN: AWMHF

- Source Type: Journal

- Original language: English

- DOI: $10.1007 / \mathrm{s} 00737-017-0727-8$

- Document Type: Letter

- Publisher: Springer-Verlag Wien 